\title{
A practical algorithm for estimating surface soil moisture using combined optical and thermal infrared data
}

\author{
Pei Leng ${ }^{\mathrm{a}}$, Xiaoning Song ${ }^{\mathrm{b}}$, Si-Bo Duan ${ }^{\mathrm{a}}$, Zhao-Liang $\mathrm{Li}^{\mathrm{a}, \mathrm{c}, *}$

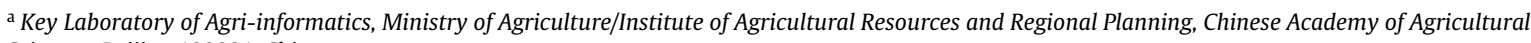 \\ Sciences, Beijing 100081, China \\ ${ }^{\mathrm{b}}$ College of Resources and Environment, University of Chinese Academy of Sciences, Beijing 100049, China \\ c Stake Key Laboratory of Resources and Environmental Information System, Institute of Geographic Sciences and Natural Resources Research, Chinese \\ Academy of Sciences, Beijing 100101, China
}

\section{A R T I C L E I N F O}

\section{Article history:}

Received 23 April 2016

Received in revised form 4 July 2016

Accepted 7 July 2016

Available online 18 July 2016

\section{Keywords:}

Surface soil moisture (SSM)

Historical meteorological records

Daily maximum solar radiation

Optical and thermal infrared

\begin{abstract}
A B S T R A C T
Surface soil moisture (SSM) is a critical variable for understanding the energy and water exchange between the land and atmosphere. A multi-linear model was recently developed to determine SSM using ellipse variables, namely, the center horizontal coordinate $\left(x_{0}\right)$, center vertical coordinate $\left(y_{0}\right)$, semi-major axis $(a)$ and rotation angle $(\theta)$, derived from the elliptical relationship between diurnal cycles of land surface temperature (LST) and net surface shortwave radiation (NSSR). However, the multi-linear model has a major disadvantage. The model coefficients are calculated based on simulated data produced by a land surface model simulation that requires sufficient meteorological measurements. This study aims to determine the model coefficients directly using limited meteorological parameters rather than via the complicated simulation process, decreasing the dependence of the model coefficients on meteorological measurements. With the simulated data, a practical algorithm was developed to estimate SSM based on combined optical and thermal infrared data. The results suggest that the proposed approach can be used to determine the coefficients associated with all ellipse variables based on historical meteorological records, whereas the constant term varies daily and can only be determined using the daily maximum solar radiation in a prediction model. Simulated results from three FLUXNET sites over 30 cloud-free days revealed an average root mean square error (RMSE) of $0.042 \mathrm{~m}^{3} / \mathrm{m}^{3}$ when historical meteorological records were used to synchronously determine the model coefficients. In addition, estimated SSM values exhibited generally moderate accuracies (coefficient of determination $R^{2}=0.395$, RMSE $=0.061 \mathrm{~m}^{3} / \mathrm{m}^{3}$ ) compared to SSM measurements at the Yucheng Comprehensive Experimental Station.
\end{abstract}

(c) 2016 Elsevier B.V. All rights reserved.

\section{Introduction}

Soil moisture content usually refers to the water contained in the unsaturated soil zone (Seneviratne et al., 2010). As a crucial part of the soil moisture content, land surface soil moisture (SSM) is a critical parameter that largely controls the energy and water exchange between the land and atmosphere (Eltahir, 1998; Entekhabi and Rodriquez-Iturbe, 1994). Accurately estimating SSM is of high relevance to a number of bio-physical processes that closely related to various fundamental research and practical applications, especially for the energy, mass and water between the atmosphere, bio-

\footnotetext{
* Corresponding author at: Key Laboratory of Agri-informatics, Ministry of Agriculture/Institute of Agricultural Resources and Regional Planning, Chinese Academy of Agricultural Sciences, Beijing 100081, China.

E-mail address: lizl@unistra.fr (Z.-L. Li).
}

sphere and hydrosphere (Johnsson and Jansson, 1991; Li et al., 2009, 2013a,b; Sanchez-Mejia and Papuga, 2014; Duan et al., 2014a; Ferguson et al., 2016). For instance, SSM is widely recognized as a key variable in climate systems, playing a major role in climate change projections (Seneviratne et al., 2010; Mittelbach et al., 2011; AI-Yaari et al., 2014) and global change studies (Henderson-Sellers, 1996; Falloon et al., 2011; Dorigo and de Jeu, 2016). In the agricultural application, accurate monitoring of SSM is quite benefit to almost all stages of crop growth, and is also of great importance to detect agricultural drought and for yield estimates (Holzman et al., 2014; Carrão et al., 2016). Moreover, SSM is also considered as a significant component of the hydrological cycle, effectively controlling the partition of rainfall into infiltration and runoff (Anderson et al., 2009; Tuttle and Salvucci, 2014; Laiolo et al., 2016).

Quantitative SSM values, particularly at the regional and global scales, are useful in the aforementioned context. Therefore, a number of studies have focused on obtaining regional or global 


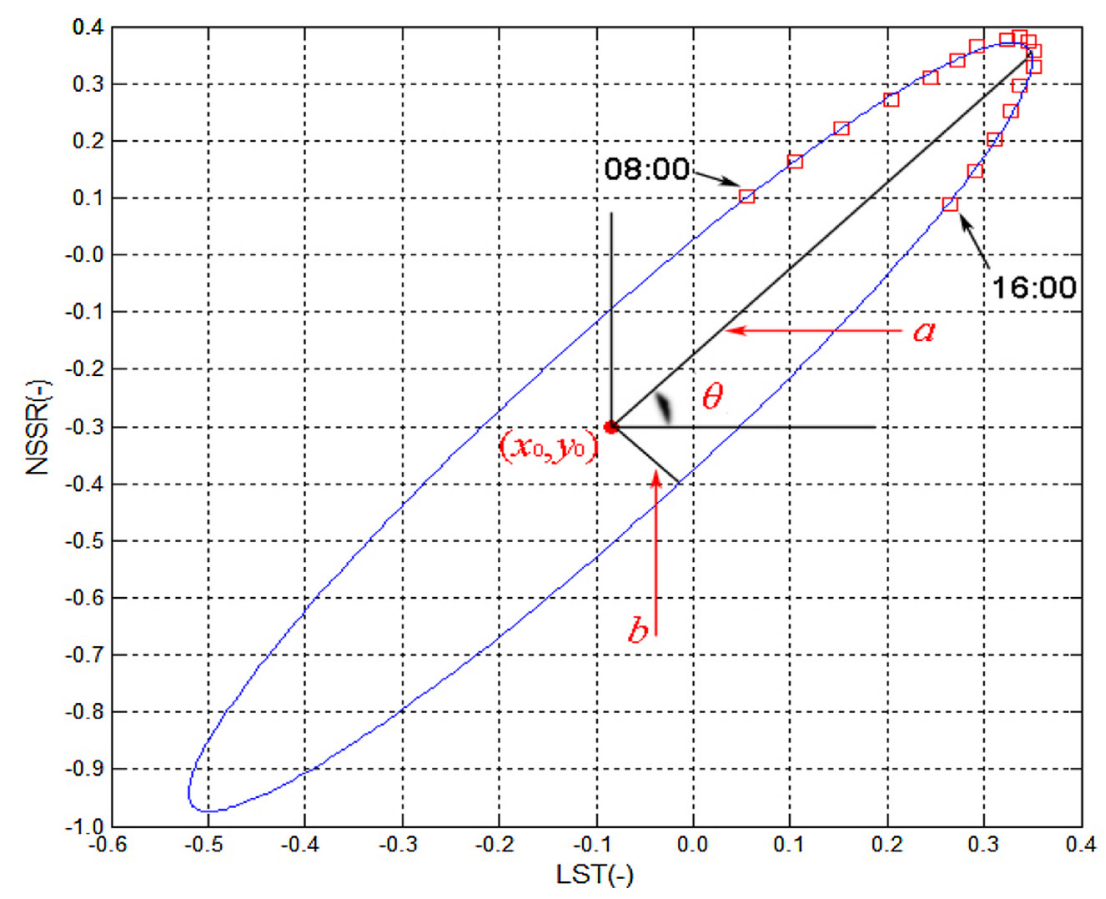

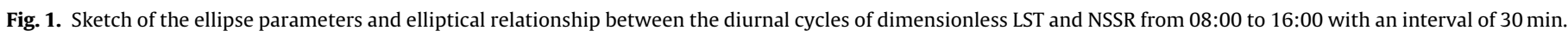

scale SSM values, especially in recent decades due to advances in the acquisition of remote sensing observations and algorithm development. These remote sensing methods for SSM retrieval can be simply divided into two categories: the one is singleband based algorithms. In this category, the optical band-derived spectral reflectance and the thermal infrared band-derived thermal inertia are two most commonly used methods (Price, 1977; Adegoke and Carleton, 2002; Lesaignoux et al., 2013); the other is using multi-band remote sensing data. This category mainly includes three forms of multi-band combination, namely, combining optical and thermal infrared data (Wetzel et al., 1984; Sandholt et al., 2002), combining optical and microwave data (Mattar et al., 2012; Santamaría-Artigas et al., 2016), and combining thermal infrared and microwave data (Chauhan et al., 2003; Sobrino et al., 2012; Notarnicola et al., 2012). In these algorithms, the feature space between optical-derived vegetation index (VI) and thermal infrared-derived surface temperature and the following indices developed on the basis of the feature space, have been widely implemented for estimating SSM with various images all over the world. In addition to these algorithms, many polar orbit and geostationary satellites have been successfully launched into space and are currently in operation, providing a variety of data for SSM estimation across the world. Specifically, several global SSM products have been successfully developed and can be publicly accessed (http://www.esa-soilmoisture-cci.org/ , http://nsidc.org/data/amsre/, http://www.catds.fr/, http://www. nasa.gov/smap/). Although these SSM data sets have been previously used in many fields, the currently available SSM data sets are primarily based on microwave observations, and several limitations have prevented further use of SSM products in various applications. Using the Advanced Scatterometer (ASCAT) soil moisture product as an example, only count values from zero to one hundred (rather than the real volumetric water content) are provided to represent the extremely dry to extremely wet conditions. Consequently, these values must generally be converted into absolute soil moisture content using time series analysis or auxiliary data such as soil porosity or other soil moisture data sets (Wagner et al., 1999; Ceballos et al., 2005; Draper et al., 2011; Pierdicca et al., 2013). Although SSM data sets such as the commonly used Advanced Microwave Scanning Radiometer-Earth Observing System (AMSR-E) and Soil Moisture and Ocean Salinity (SMOS) have been developed based on radiative transfer models, the challenge is that they require the input of many physical parameters, some of which are currently not well-defined, e.g. vegetation cover in target frequencies and the emission properties of the soil surface (Pan et al., 2014). This challenge is most likely to make the accuracies of the currently available passive microwave-based SSM products must be further verified and improved (Coopersmith et al., 2015). Moreover, the coarse spatial resolution is also a critical issue that has greatly limited the application of these SSM products in relatively small regions, often leading to difficulties detecting sub-pixel variations (Merlin et al., 2010).

Compared with microwave-based SSM products, optical and thermal infrared remotely sensed observations typically possess finer spatial resolutions that are better for various applications. Moreover, the theoretical basis associated with the commonly used optical and thermal infrared SSM retrieval methods is generally more advanced than microwave remote sensing retrieval methods. Nevertheless, a prominent issue associated with these optical and thermal infrared-based algorithms is that the real volumetric water content cannot be directly obtained. Empirical or statistical relationships between the remotely sensed proxies and ground SSM measurements are generally needed to estimate regional SSM. Consequently, no actual, operational thermal infrared-and/or optical-based SSM products are currently available.

A novel SSM retrieval model that combines diurnal cycles of land surface temperature (LST) and net surface shortwave radiation (NSSR) on cloud-free days has recently been developed based on these limitations. The simulated data are produced via a land surface model simulation process (Leng et al., 2014). Specifically, this model has been used to directly and quantitatively estimate SSM without establishing empirical relationships between remotely sensed proxies and SSM measurements, differing from other commonly used optical and thermal infrared observation-based SSM retrieval methods. Nevertheless, this SSM retrieval model suffers from a major problem. Although the five model coefficients in the 


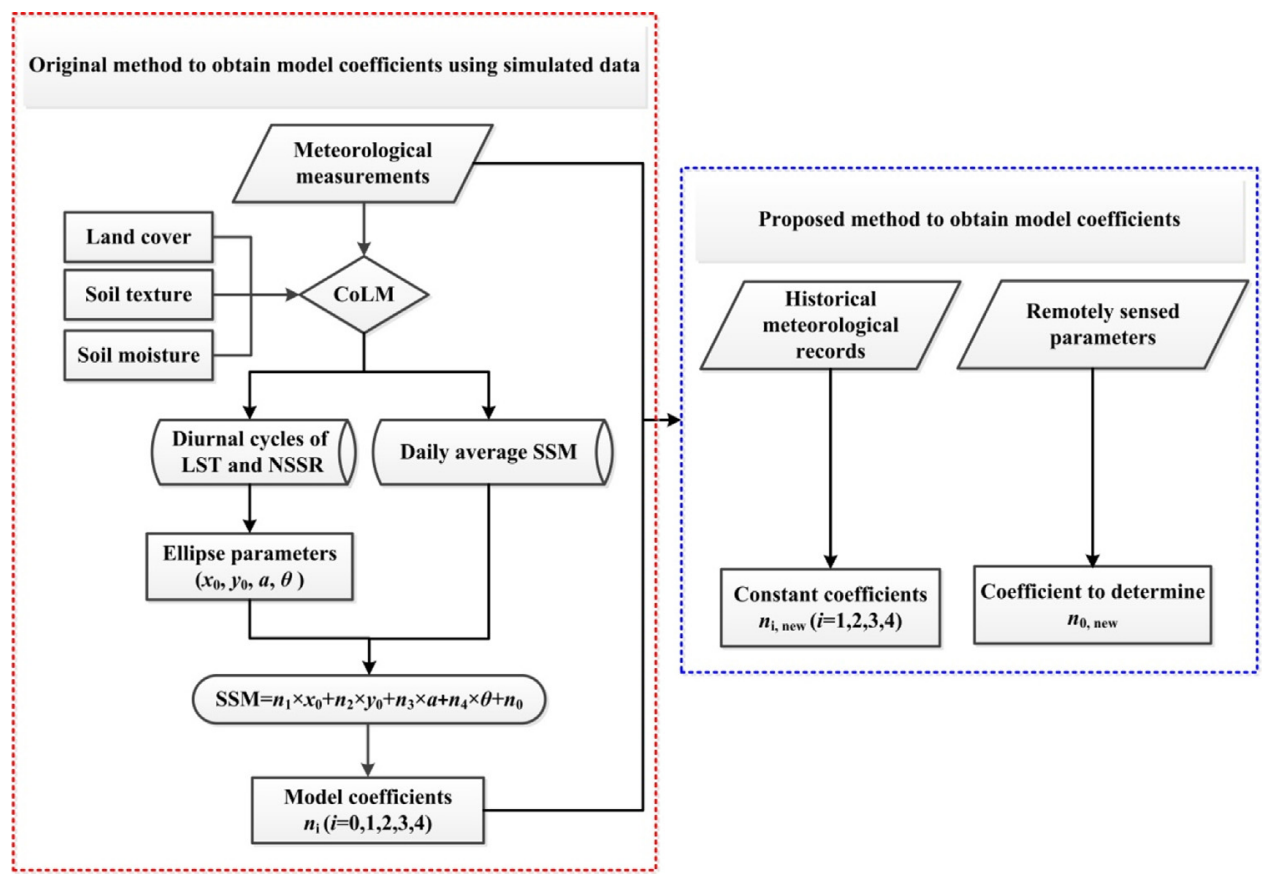

Fig. 2. Land surface model simulation and model coefficient determination.

SSM retrieval model depend on daily meteorological conditions, no direct method is available to determine the model coefficients directly using the meteorological measurements. The five model coefficients must be obtained via a land model simulation process, in which sufficient meteorological measurements (including solar radiation, downward longwave radiation, precipitation, air temperature, wind speed, wind direction, air pressure and relative humidity) must be provided as time series at a certain temporal resolution on cloud-free days. This disadvantage makes the SSM retrieval model inconvenience to use, especially with the geostationary satellite images. In a previous study (Leng et al., 2015), a calibration method was attempted to obtain the model coefficients over the REMEDHUS network (Spain) using combined in-situ SSM measurements and the Meteosat Second Generation (MSG) images. Although the calibrated coefficients revealed good results between estimated SSM and ground SSM measurements, the calibration process is generally complicated, and a number of in-situ SSM measurements are required. In particular, the inevitable scale issue between the MSG pixel and ground site scale SSM measurements is one of the major error sources in the calibration method.

In summary, determination of the model coefficients from both the simulated data and the calibration method are not practical, resulting in difficulties for the routine use of the SSM retrieval model, especially in the future development with geostationary satellite images to routinely map regional SSM. Specifically, method form simulated data requires numerous observational parameters and rigid temporal continuity, whereas the calibration method demands sufficient in-situ SSM measurements and confronts the inevitable scale issue. Hence, it is quite necessary to develop more convenient and practical methods for determining the model coefficients. This study, starting from the previously developed SSM retrieval model and the existing disadvantage that the model coefficients depend only on the meteorological conditions during each individual cloud-free day, aims at developing a practical algorithm for calculating model coefficients and estimating SSM using combined optical and thermal infrared data.

In the context, because the model coefficients are closely related to meteorological parameters, the proposed procedure is to maximize the potential for using historical meteorological records to determine model coefficients, which is an effectively way to decrease the requirements of the SSM retrieval model with respect to meteorological measurements in current or future application stages. This idea is motivated by the fact that the model coefficients exhibit only small fluctuation in time series for a giving study area. Hence, using the historical meteorological records is most likely to provide a wealth of information that enables to make some of the coefficients constant, thus contributing to decrease the number of coefficients must be determined when implementing the SSM retrieval model (Zhao et al., 2013). Moreover, investigating the explicit relationships between the model coefficients and meteorological measurements enables to determine the model coefficients directly using only limited meteorological parameters, which is a promising approach for decreasing the dependence of the model coefficients on meteorological measurements with respect to both temporal continuity and the required multiple necessary meteorological elements. Specifically, obtaining the model coefficients using direct instantaneous (rather than time series) meteorological measurements via a land surface model simulation will make the model easier to use and will benefit future model applications.

\section{Materials and methods}

\subsection{Overview of the SSM retrieval model}

In a previous study, a novel SSM retrieval model was developed using temporal LST and NSSR variations on cloud-free days (Leng et al., 2014). The model can be written as follows:

$\mathrm{SSM}=n_{1} \times x_{0}+n_{2} \times y_{0}+n_{3} \times a+n_{4} \times \theta+n_{0}$

where SSM is the daily average $\operatorname{SSM}\left(\mathrm{m}^{3} / \mathrm{m}^{3}\right) ; x_{0}, y_{0}, a$ and $\theta$ are the ellipse parameters derived from the elliptical relationship between the diurnal LST and NSSR cycles, i.e., the horizontal coordinate of the ellipse center, vertical coordinate of the ellipse center, semimajor axis and rotation angle, respectively; and $n_{i}(i=0,1,2,3,4)$ represents the model coefficients $\left(\mathrm{m}^{3} / \mathrm{m}^{3}\right)$. Fig. 1 depicts an ellipse between dimensionless multi-temporal LST and NSSR from 08:00 to $16: 00$, with an interval of 30 min from field measurements. 
Table 1

A brief description of the study sites.

\begin{tabular}{|c|c|c|c|c|c|}
\hline Site name & Latitude, Longitude & Elevation (m) & Land use type & Climate pattern & Data period \\
\hline Audubon Research Ranch & $31.5907^{\circ} \mathrm{N},-110.5092^{\circ} \mathrm{W}$ & 1469 & desert grassland & temperate arid & $2003-2011$ \\
\hline Brookings & $44.3453^{\circ} \mathrm{N},-96.8362^{\circ} \mathrm{W}$ & 495 & range grassland & humid continental & $2004-2010$ \\
\hline Santa Rita Mesquite & $31.8214^{\circ} \mathrm{N},-110.8661^{\circ} \mathrm{W}$ & 1118 & open shrublands & subtropical & 2004-2012 \\
\hline
\end{tabular}

Table 2

Calibration and validation periods at the three FLUXNET sites.

\begin{tabular}{|c|c|c|c|c|}
\hline \multirow[t]{2}{*}{ Site name } & \multicolumn{2}{|l|}{ Calibration } & \multicolumn{2}{|l|}{ Validation } \\
\hline & Years & Number of cloud-free days & Years & Number of cloud-free days \\
\hline Audubon Research Ranch & $2003-2008$ & 426 & 2009-2011 & 193 \\
\hline Brookings & 2004-2008 & 265 & 2009-2010 & 85 \\
\hline Santa Rita Mesquite & 2004-2009 & 482 & 2010-2012 & 243 \\
\hline
\end{tabular}

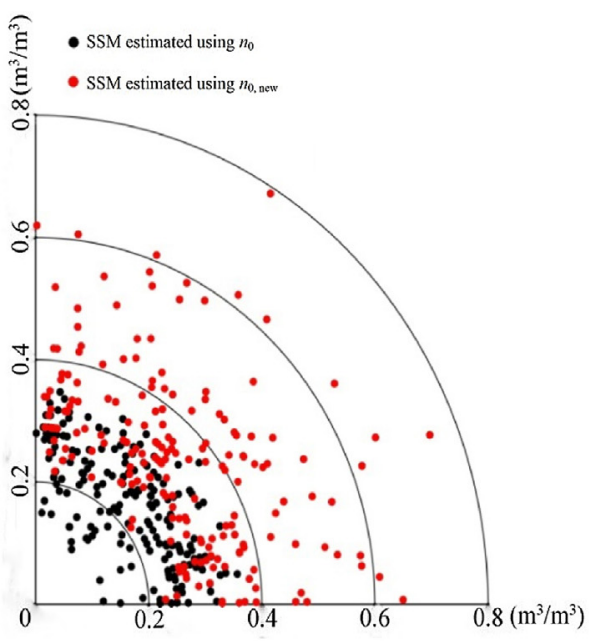

(a) Audubon Research Ranch

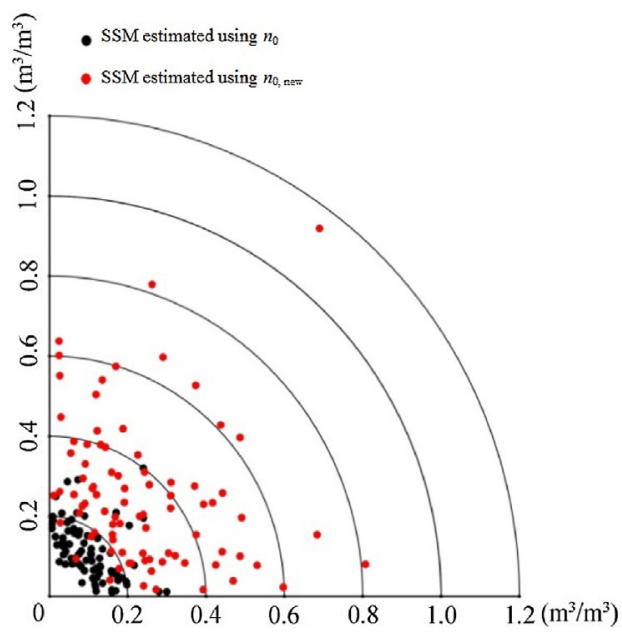

(b) Brookings

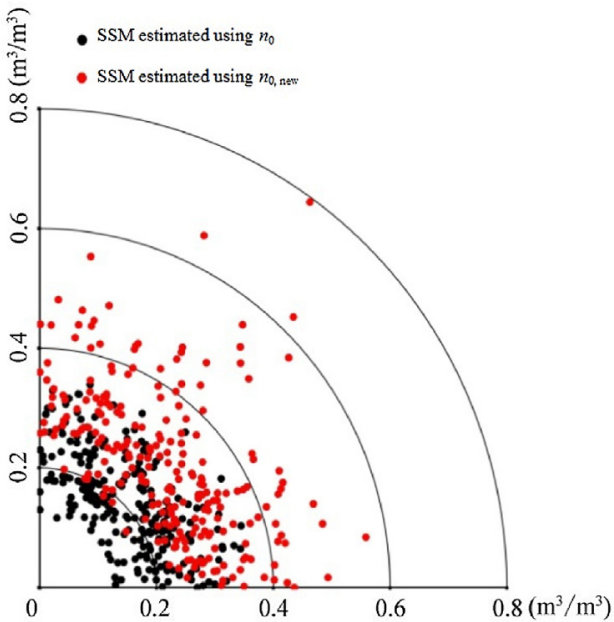

(c) Santa Rita Mesquite

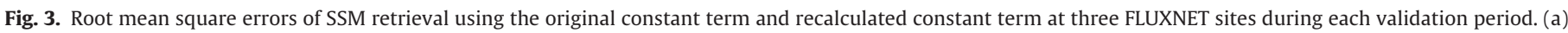
Audubon Research Ranch; (b) Brookings; and (c) Santa Rita Mesquite.

During the application of the SSM retrieval model, the ellipse parameters $\left(x_{0}, y_{0}, a\right.$ and $\left.\theta\right)$ can be obtained at the pixel-scale based on the ellipse associated with the geostationary satellite-derived diurnal LST and NSSR cycles. The remaining issue associated with implementing the SSM retrieval model is obtaining the five model coefficients $n_{i}(i=0,1,2,3,4)$ on each cloud-free day.

\subsection{Determination of model coefficients}

In a previous study (Leng et al., 2013), the five model coefficients $n_{i}(i=0,1,2,3,4)$ are obtained using simulated dataset produced by the Common Land Model (CoLM) simulation. Fig. 2 depicts the CoLM simulation and coefficient determination proce- 
dures in detail. Specifically, the red dotted rectangle on the left side of Fig. 2 is the original method used to obtain the model coefficients based on CoLM-simulated data, and the right blue dotted rectangle represents the objective of this study, which is to develop a new method for determining model coefficients.

Because the values of the five model coefficients $n_{i}(i=0,1,2,3$, 4) vary daily and depend on meteorological measurements that are used as atmospheric forcing data to drive the CoLM simulation, it is difficult to determine all five of these coefficients using meteorological elements. Furthermore, because the latter four coefficients $n_{i}(i=1,2,3,4)$ are associated with the four ellipse variables $\left(x_{0}, y_{0}\right.$, $a$ and $\theta$ ), it is reasonable to assume that these four coefficients $n_{i}$ $(i=1,2,3,4)$ are constant, i.e., independent of atmospheric conditions. Thus, they can be determined using historical meteorological measurements. As a result, all the uncertainties associated with these four terms are transferred to the constant term $n_{0}$. Only the constant term $n_{0}$ varies with atmospheric conditions. Thus, it should be easily determined using conventional meteorological measurements available based on remotely sensed parameters. This assumption generally has two potential advantages. First, the four constant coefficients can be established using historical meteorological records, benefiting the use of the SSM retrieval model in present and future stages. Second, calculating the constant term $n_{0}$ requires only a few meteorological measurements. Moreover, these measurements are expected to be available directly from remotely sensed parameters. Thus, the assumption effectively decreases the meteorological measurements required to obtain the model coefficients compared to the requirements of the original method.

\subsection{Land surface model simulation}

The relationships between model coefficients and meteorological measurements should be explored to develop a new method for determining model coefficients using historical meteorological records, especially for different locations, elevations, land use types and climate patterns. In this context, data simulated by CoLM are used to investigate the feasibility of determining the model coefficients directly using historical meteorological records. Specifically, cloud-free day meteorological measurements from three FLUXNET (http://www.fluxnet.ornl.gov/) sites in the USA are used in this study, namely, Audubon Research Ranch, Brookings and Santa Rita Mesquite. Because the meteorological/flux measurements at the FLUXNET sites can be freely accessed, all of the available meteorological/flux data measured at the three FLUXNET sites were collected in this study. Brief introductions to these three sites are provided in Table 1.

Only days between the 100th and 300th day of the year (DOY) are considered to avoid possible freeze/thaw conditions. Furthermore, cloud-free days at the three sites are selected if the measured solar radiation exhibits a regular cosine variation during the daytime. Ultimately, meteorological elements (including solar radiation, downward longwave radiation, precipitation, air temperature, wind speed, wind direction, air pressure and relative humidity) collected at the three sites at intervals of $30 \mathrm{~min}$ are used to drive the CoLM and produce simulated data for further investigation.

Simulated data from the three sites are divided into two sets, representing a calibration period and a validation period. The model coefficients are determined during the calibration period, whereas the feasibility of SSM estimation using the model coefficients derived during the calibration period is investigated during the validation period. Table 2 provides the number of cloud-free days at the three FLUXNET sites during both the calibration and validation periods.

Because the four coefficients $n_{i}(i=1,2,3,4)$ associated with the four ellipse variables $\left(x_{0}, y_{0}, a\right.$ and $\left.\theta\right)$ are assumed constant, we first set the average coefficient values $\overline{n_{i}}(i=1,2,3,4)$ from the calibration period equal to the constant model coefficients, which can be calculated as follows:

$$
\overline{n_{i}}=\frac{\sum_{j=1}^{m} n_{i, j}}{m}(i=1,2,3,4)
$$

where $\overline{n_{i}}$ represents the constant model coefficients determined using the simulated data during the calibration period, $n_{i, j}$ represents the coefficients $\overline{n_{i}}(i=1,2,3,4)$ calculated on cloud-free day $j$ and $m$ is the number of cloud-free days at each site during the calibration period.

The new constant term $n_{0}$ can be calculated for each day using these four constant coefficients $\overline{n_{i}}(i=1,2,3,4)$ :

$$
n_{0, \text { new }}=\frac{\sum_{k=1}^{A} S S M_{s i m, k}-\sum_{k=1}^{A}\left(\overline{n_{1}} \times x_{0, k}+\overline{n_{2}} \times y_{0, k}+\overline{n_{3}} \times a_{k}+\overline{n_{4}} \times \theta_{k}\right)}{A}
$$

where $n_{0, \text { new }}$ is the new constant term calculated on each cloudfree day and $A$ is the total number of simulations on each cloud-free day. For each simulation, a unique combination of soil texture and soil moisture is used to represent a possible underlying surface condition and initialize the CoLM for bare soils. Specifically, 12 soil textures from the soil texture classification scheme of the Food and Agriculture Organization (FAO) are implemented in the CoLM simulation. For each soil texture, 10 intervals of initial soil moisture ranging from a minimum value (near the wilting point) to a maximum value (approaching the saturated moisture content) are used to represent different soil moisture levels. Hence, $120(12 \times 10)$ simulations were performed using CoLM on each cloud-free day. $S S M_{\text {sim }, k}$ is the simulated SSM value of the $k^{\text {th }}$ simulation in CoLM on a given cloud-free day. $x_{0, k}, y_{0, k}, a_{k}$ and $\theta_{k}$ represent the horizontal coordinate of the ellipse center, vertical coordinate of the ellipse center, semi-major axis and rotation angle, respectively, of the $k^{\text {th }}$ simulation on a given cloud-free day.

\section{Results and analysis}

\subsection{SSM retrieval using the new constant term $n_{0, \text { new }}$ during the validation period}

The constant model coefficients $\overline{n_{i}}(i=1,2,3,4)$ for the three FLUXNET sites are determined using Eq. (2) based on simulated data over the calibration period. The new constant term $n_{0 \text {, new }}$ for each cloud-free day is calculated using Eq. (3) during the validation period. SSM values during the validation period are estimated via the SSM retrieval model in Eq. (1) using the model coefficients. Fig. 3 depicts the root mean square errors (RMSE) of SSM retrieval using the original model coefficients $n_{i}(i=0,1,2,3,4)$ and new coefficient $\left(n_{0, \text { new }}\right.$ and $\left.\overline{n_{i}}(i=1,2,3,4)\right)$ at the three FLUXNET sites.

The results show that the RMSEs on cloud-free days during the validation period are within $0.04 \mathrm{~m}^{3} / \mathrm{m}^{3}$, indicating that the SSM retrieval model yields significantly high accuracies when using the original model coefficients. Using the constant model coefficients $\overline{n_{i}}(i=1,2,3,4)$ and the new constant term $n_{0, \text { new }}$ to estimate SSM during the validation period also produced satisfactory accuracies. The majority of cloud-free days at the three FLUXNET sites during the validation period displayed positive results when the new constant term $n_{0, \text { new }}$ is used to estimate SSM. In particular, an average of $70 \%$ of the cloud-free days at the three sites exhibited RMSEs within $0.04 \mathrm{~m}^{3} / \mathrm{m}^{3}$.

In addition, only a few cloud-free days displayed RMSEs over $0.06 \mathrm{~m}^{3} \mathrm{~m}^{-3}$ when the new model coefficients were used to estimate SSM. Specifically, approximately $6 \%$ and $10 \%$ of cloud-free 
Table 3

Absolute correlation coefficient between the constant term $n_{0}$ and meteorological parameters.

\begin{tabular}{|c|c|c|c|c|c|c|c|c|}
\hline Site name & Constant term & $\begin{array}{l}\text { Solar radiation } \\
\text { at } 6: 00\end{array}$ & $\begin{array}{l}\text { Maximum solar } \\
\text { radiation }\end{array}$ & $\begin{array}{l}\text { Average air } \\
\text { temperature }\end{array}$ & $\begin{array}{l}\text { Wind speed at } \\
6: 00\end{array}$ & $\begin{array}{l}\text { Average wind } \\
\text { speed }\end{array}$ & $\begin{array}{l}\text { Average air } \\
\text { pressure }\end{array}$ & $\begin{array}{l}\text { Average relative } \\
\text { humidity }\end{array}$ \\
\hline \multirow{4}{*}{$\begin{array}{l}\text { Audubon Research } \\
\text { Ranch } \\
\text { Brookings }\end{array}$} & original $n_{0}$ & 0.279 & 0.363 & 0.235 & 0.320 & 0.322 & 0.115 & 0.348 \\
\hline & $n_{0, \text { new }}$ & 0.638 & 0.961 & 0.221 & 0.556 & 0.230 & 0.468 & 0.354 \\
\hline & original $n_{0}$ & 0.119 & 0.247 & 0.063 & 0.155 & 0.074 & 0.060 & 0.167 \\
\hline & $n_{0, \text { new }}$ & 0.737 & 0.987 & 0.469 & 0.154 & 0.127 & 0.342 & 0.159 \\
\hline \multirow[t]{2}{*}{ Santa Rita Mesquite } & original $n_{0}$ & 0.517 & 0.618 & 0.567 & 0.233 & 0.061 & 0.360 & 0.213 \\
\hline & $n_{0, \text { new }}$ & 0.409 & 0.988 & 0.272 & 0.348 & 0.037 & 0.456 & 0.255 \\
\hline
\end{tabular}

days at Audubon Research Ranch and Brooking, respectively, exhibited RMSEs over $0.06 \mathrm{~m}^{3} / \mathrm{m}^{3}$. In particular, only three of 243 cloud-free days at Santa Rita Mesquite exhibited RMSEs over $0.06 \mathrm{~m}^{3} / \mathrm{m}^{3}$. These results demonstrate that different external environments affect the SSM retrieval model differently when using constant model coefficients $\overline{n_{i}}(i=1,2,3,4)$ and the new constant term $n_{0, \text { new }}$ to estimate SSM. Although it may slightly decrease the accuracy, the new coefficients can generally achieve acceptable results, with average RMSEs of $0.038 \mathrm{~m}^{3} / \mathrm{m}^{3}, 0.039 \mathrm{~m}^{3} / \mathrm{m}^{3}$ and $0.033 \mathrm{~m}^{3} / \mathrm{m}^{3}$ at Audubon Research Ranch, Brookings and Santa Rita Mesquite, respectively, during the validation period.

\subsection{Correlation analysis of the constant term and meteorological elements}

The previous section primarily demonstrates the feasibility of using constant model coefficients $\overline{n_{i}}(i=1,2,3,4)$ and the new constant term $n_{0, \text { new }}$ to estimate SSM. As illustrated in the previous section, the constant model coefficients can be determined using historical meteorological measurements, and only the constant term $n_{0, \text { new }}$ must be obtained before the SSM retrieval model can be implemented for routine applications. Determining the new constant term $n_{0, \text { new }}$ using Eq. (3) over the validation period requires simulated data via a land surface model simulation process. Adequate atmospheric forcing data (including solar radiation, downward longwave radiation, precipitation, air temperature, wind speed, wind direction, air pressure and relative humidity) are required by the model. Additionally, the quantity, quality and continuity of the meteorological observations must strictly conform to the model requirements.

To develop a new method for determining the new constant term $n_{0, \text { new }}$ directly using instantaneous meteorological parameters, a correlation analysis is first conducted to investigate the relationships between the new constant term $n_{0, \text { new }}$ and the meteorological measurements at the three sites over the validation period. Simulated data are produced via land surface model simulations that use time series of meteorological elements for atmospheric forcing, yielding different results than simulations that use instantaneous meteorological observations. Several parameters that capture the main features of meteorological evolution on cloud-free days are selected for the correlation analysis. For example, because solar radiation generally exhibits regular cosine evolution during the daytime, solar radiation at 6:00 am and daily maximum solar radiation are selected to represent the influences of solar radiation in the analysis. Moreover, we also examined the auto-correlation associated with each selected meteorological element, keeping only the parameters that best represent each associated meteorological element. For example, because air temperature at 6:00 a.m., daily maximum air temperature and daily average air temperature are correlative, only average air temperature is selected to represent the influence of air temperature in the correlation analysis.

Table 3 shows the absolute correlation coefficients between the constant term $n_{0}$ and the selected meteorological parameters at the three FLUXNET sites over the validation period. The results

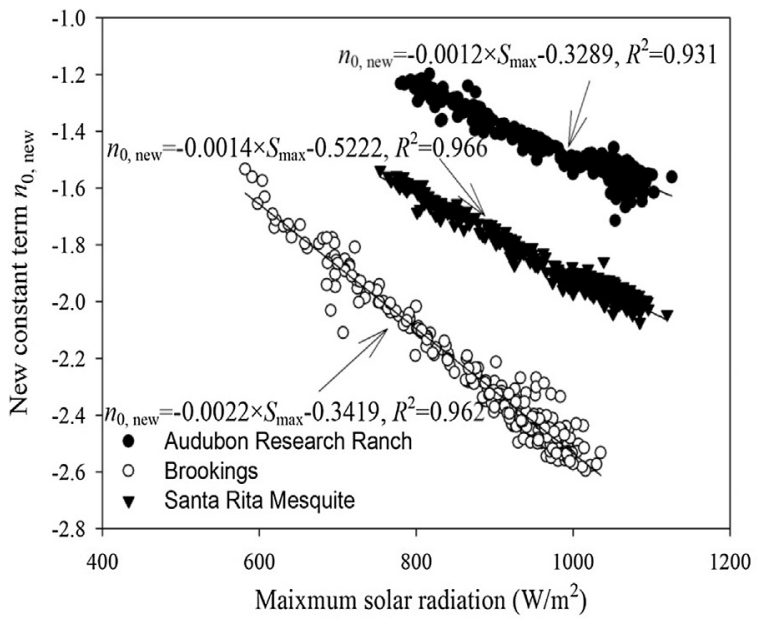

Fig. 4. Linear relationships between the new constant term $n_{0, \text { new }}$ and daily maximum solar radiation $\left(S_{\max }\right)$ over the calibration period

generally exhibited poor correlation coefficients, except for those between the new constant term $n_{0 \text {,new }}$ and maximum solar radiation. These correlation coefficients were significant at all three FLUXNET sites. These results indicate the potential feasibility of using only the daily maximum solar radiation to determine the new constant term $n_{0, \text { new }}$. Compared with using all of the necessary meteorological elements in time series as atmospheric forcing data to determine the model coefficients in an indirect manner via the land surface model simulation process, using only daily maximum solar radiation to determine $n_{0 \text {, new }}$ is much more concise and practical.

\subsection{Determination of the constant term $n_{0, \text { new }}$ using daily maximum solar radiation}

The correlation analysis presented in the previous section can be used to determine the new constant term $n_{0, \text { new }}$ directly using daily maximum solar radiation. However, one remaining issue is associated with determining the linear relationship between the new constant term $n_{0, \text { new }}$ and daily maximum solar radiation in a particular study area. Thus, this study aims to develop a specific prediction model for deriving $n_{0, \text { new }}$ using only daily maximum solar radiation from historical records of meteorological measurements.

Fig. 4 depicts the scatter plots and linear fitting between the new constant term $n_{0}$ and daily maximum solar radiation $\left(S_{\max }\right)$ over the calibration period at the three FLUXNET sites. Fig. 4 shows significant linear relationships at the three FLUXNET sites, with an average coefficient of determination over 0.95 , indicating that the proposed prediction models are able to capture the relationship between the constant term $n_{0 \text {, new }}$ and daily maximum solar radiation.

The viabilities of the proposed prediction models are further assessed using measured daily maximum solar radiation to obtain the new constant term $n_{0 \text {, new }}$ over the validation period. Fig. 5 depicts the scatter plots of the new constant term $n_{0 \text {,new }}$ obtained 


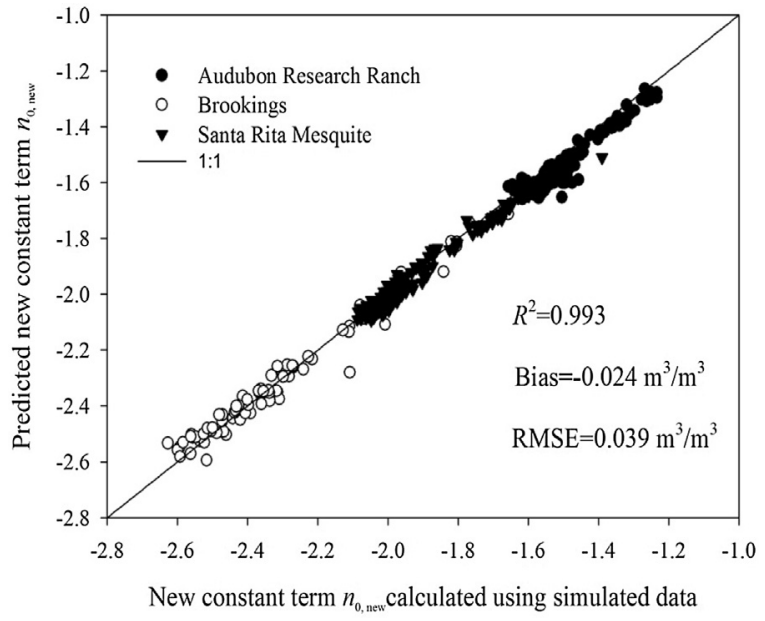

Fig. 5. Scatter plots of the simulated data-derived constant term $n_{0, \text { new }}$ versus predicted $n_{0, \text { new. }}$

using two approaches. The first approach establishes the abscissa axis as $n_{0 \text {,new }}$ using Equation ( 3 ) from the simulated data. The second approach establishes the ordinate axis as the new predicted constant term $n_{0, \text { new }}$ using the prediction models shown in Fig. 4. Note that the fundamental difference between these two $n_{0 \text {,new }}$ data sets is that the ordinate axis approach only requires the daily maximum solar radiation as input to calculate the constant term $n_{0, \text { new }}$. The prediction models can be determined using historical meteorological measurements, whereas the abscissa approach requires large simulated data sets based on continuous meteorological measurements as atmospheric forcing data to drive land surface models.

It is evident that these two data sets are significantly correlated $\left(R^{2}=0.993\right)$ and distributed equally around the $1: 1$ line, with a Bias of $-0.024 \mathrm{~m}^{3} / \mathrm{m}^{3}$ and an RMSE of $0.039 \mathrm{~m}^{3} / \mathrm{m}^{3}$ at the three FLUXNET sites. Although these two data sets exhibit some differences, using the predicted constant term $n_{0 \text {,new }}$ to estimate SSM is generally feasible. Moreover, the daily maximum solar radiation can be obtained using geostationary satellite data. For example, Meteosat Second Generation (MSG) has provided Downward Surface Shortwave Flux (DSSF) data at a temporal resolution of $30 \mathrm{~min}$ for surface radiation budget calculations. This product can be used to obtain the daily maximum solar radiation. Overall, the significant linear relationship between the constant term $n_{0 \text {, new }}$ and daily maximum solar radiation suggests that this vital parameter $\left(n_{0, \text { new }}\right)$ can be directly obtained using remotely sensed parameters.

\subsection{Synchronous determination of model coefficients and the prediction model}

A simple linear prediction model for deriving the constant term $n_{0, \text { new }}$ using historical records of meteorological measurements was developed in the previous section. The prediction model can be theoretically used to obtain the constant term $n_{0 \text {, new }}$ only if the daily maximum solar radiation is provided when using the SSM retrieval model. Compared with the method to calculate model coefficients using simulated data, no meteorological measurement time series or land surface model simulations are required to determine the model coefficients in the new method. In general, this approach for determining the model coefficients (hereafter denoted as method I) involves three steps. The first step is to determine the constant model coefficients $\overline{n_{i}}(i=1,2,3,4)$ using simulated data based on historical meteorological measurements. The second step is to obtain the prediction model using historical meteorological measurements and the constant model coefficients $\overline{n_{i}}(i=1,2,3,4)$ obtained in the first step. The final step is to calculate the new constant term $n_{0, \text { new }}$ with the prediction model and daily maximum solar radiation.

This section investigates a synchronous method for determining the constant model coefficients $\overline{n_{i}}(i=1,2,3,4)$ and the prediction model (hereafter denoted as method II). Because the new constant term $n_{0, \text { new }}$ reveals a significant linear relationship with the daily maximum solar radiation, the prediction model is as follows:

$n_{0, \text { new }}=p \times S_{\max }+q$

where the unknown coefficients $p$ and $q$ are the slope and intercept of the prediction model, respectively.

Specifically, unknown coefficients $p$ and $q$, together with the four constant model coefficients $\overline{n_{i}}(i=1,2,3,4)$, are synchronously calculated over the calibration period using a least square method at the three FLUXNET sites. The final equation includes six coefficients that must be determined.

$\mathrm{SSM}=\overline{n_{1}} \times x_{0}+\overline{n_{2}} \times y_{0}+\overline{n_{3}} \times a+\overline{n_{4}} \times \theta+p \times S_{\max }+q$

Using a least square method to minimize the SSM estimation error, the six coefficients are finally obtained using the simulated data and measurements of daily maximum solar radiation measurements over the calibration period at each of the FLUXNET sites. These coefficients and the prediction model are subsequently assessed based on SSM estimation results. Because 120 simulation cases are implemented in the CoLM on each cloud-free day, resulting in more values than in the simulated data set, we randomly selected 10 cloud-free days at each of the three FLUXNET sites during the validation period to investigate the SSM estimation accuracy using simulated data. Specifically, the two methods used to obtain the constant model coefficients $\overline{n_{i}}(i=1,2,3,4)$ and the prediction model, namely, method I and method II, are implemented in this study.

Fig. 6 compares the estimated SSM versus simulated values using the two approaches (method I and method II). The Audubon Research Ranch site results suggest that method II performed better than method I, whereas the opposite trend occurred at the Brookings site. Moreover, a slight decrease in accuracy occurs at the Santa Rita Mesquite site. In general, average RMSE values of $0.045 \mathrm{~m}^{3} / \mathrm{m}^{3}$ and $0.042 \mathrm{~m}^{3} / \mathrm{m}^{3}$ are obtained for method I and method II, respectively, using the simulated results. Nevertheless, it is difficult to identify the superior method. The best method is likely based on specific climate patterns and environmental variables in a study area. However, both of the methods are able to estimate SSM with acceptable accuracy using simulated data, indicating that using the historical meteorological measurements to determine the model coefficients is generally feasible.

Using the constant model coefficients $\overline{n_{i}}(i=1,2,3,4)$ and prediction model of the new constant term $n_{0, \text { new }}$, SSM can be estimated theoretically for any cloud-free day only if the daily maximum solar radiation is available during the validation period. Note that both the constant model coefficients $\overline{n_{i}}(i=1,2,3,4)$ and the prediction model of the constant term $n_{0, \text { new }}$ are theoretically determined in both methods using only historical (calibration period) meteorological measurements in this study. We emphasize this point because our goal is to simplify the method for obtaining SSM retrieval model coefficients and to decrease the dependence of the SSM retrieval model on meteorological measurements. Although preliminary evidence based on simulated data suggests that we effectively achieved this simplification, more indepth studies should be conducted in the future. 


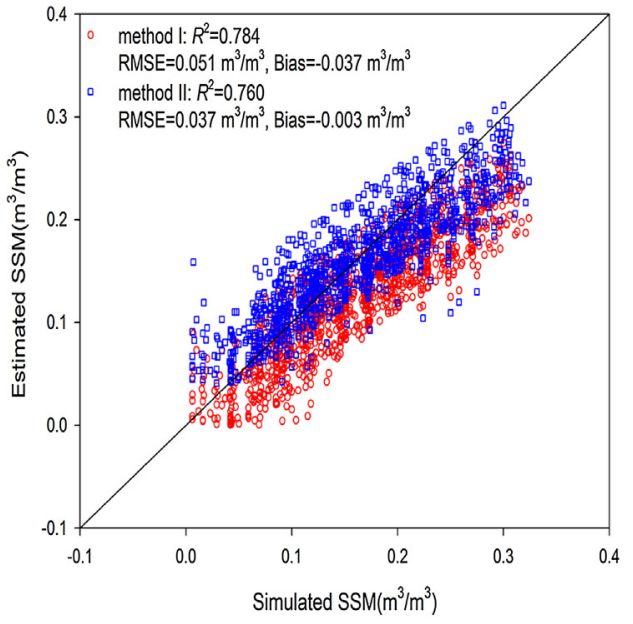

(a) Audubon Research Ranch

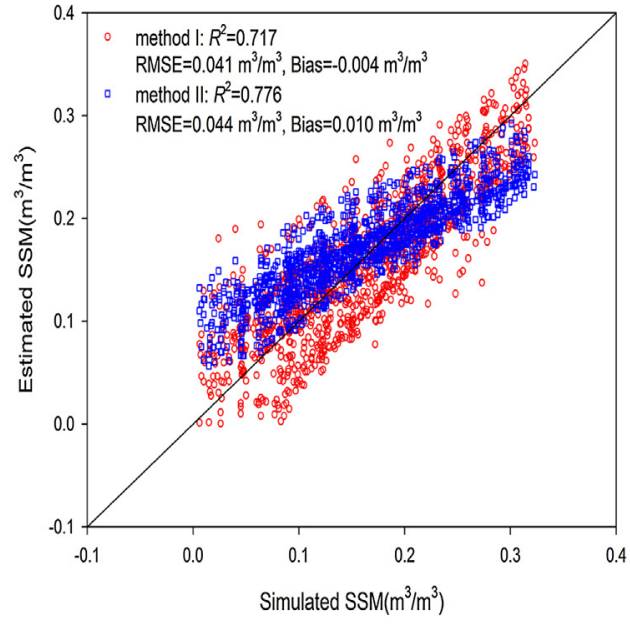

(b) Brookings

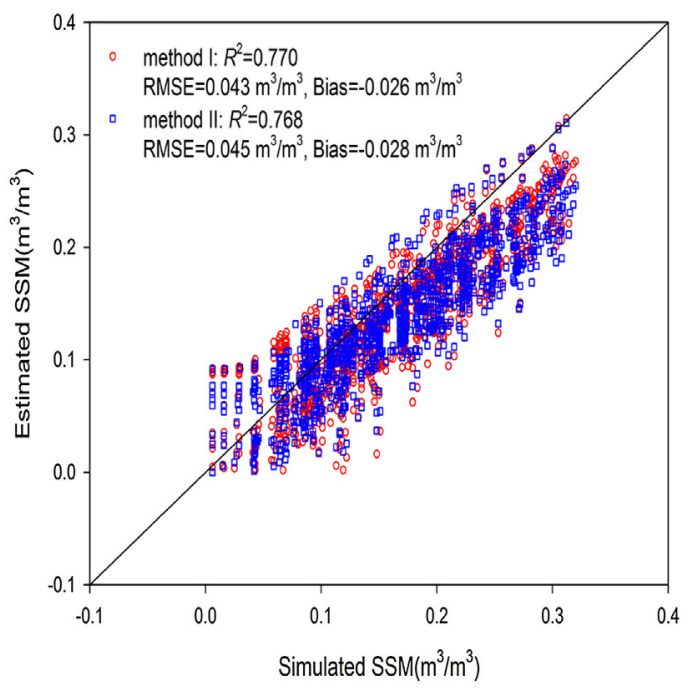

(c) Santa Rita Mesquite

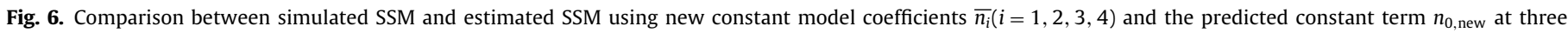
FLUXNET sites. (a) Audubon Research Ranch; (b) Brookings; and (c) Santa Rita Mesquite.

\subsection{Preliminary estimation of SSM using model coefficients obtained from historical meteorological records}

In addition to the simulated data, the Yucheng Comprehensive Experimental Station (YCES) $\left(36.8291^{\circ} \mathrm{N}, 116.5703^{\circ} \mathrm{E}\right.$, with an average elevation of $28 \mathrm{~m}$ ) in China is selected to preliminarily investigate the feasibility of estimating SSM with model coefficients obtained by both method I and method II using field measurements. Because a limited number of meteorological/flux measurements (from 2009 to 2010) were collected at YCES in this study, meteorological data from 2009 are used as calibration period data to obtain the constant model coefficients $\overline{n_{i}}(i=1,2,3,4)$ and linear prediction model for the constant term $n_{0, \text { new }}$. Moreover, 29 cloud-free days from 2010 are used to investigate the feasibility of estimating SSM based on the coefficients obtained from method I and method II.

Fig. 7 compares the ground SSM measurements and estimated SSM values based on the model coefficients obtained via three approaches. The original coefficients represent the coefficients calculated from the simulated data set for each cloud- free day. Method I and method II refer to the two methods used to obtain the constant model coefficients and prediction model for the constant term $n_{0, \text { new }}$, as shown in the previous section. In general, SSM estimates using model coefficients obtained using these three methods are well correlated to the field SSM measurements, with a moderate $R^{2}$ ranging from approximately 0.3 to 0.45 . Specifically, using the original model coefficients to estimate SSM reveals a better overall accuracy (RMSE $=0.085 \mathrm{~m}^{3} / \mathrm{m}^{3}$, Bias $=0.008 \mathrm{~m}^{3} / \mathrm{m}^{3}$ ) than those associated with method I (RMSE $=0.155 \mathrm{~m}^{3} / \mathrm{m}^{3}$, Bias $=-0.129 \mathrm{~m}^{3} / \mathrm{m}^{3}$ ) and method II $\left(\right.$ RMSE $=0.090 \mathrm{~m}^{3} / \mathrm{m}^{3}$, Bias $=-0.067 \mathrm{~m}^{3} / \mathrm{m}^{3}$ ), although the $R^{2}$ is not as significant as those of method I and method II. These results further verify the feasibility of obtaining model coefficients using land surface model simulated data. Specifically, the original method can be effectively used to determine the model coefficients only if continuous meteorological measurements are available.

Moreover, method I and method II exhibit considerable potential for obtaining the model coefficients in a simple manner. Although SSM is underestimated by both method I and method II, the $R^{2}$ values exhibit a significant improvement compared to 


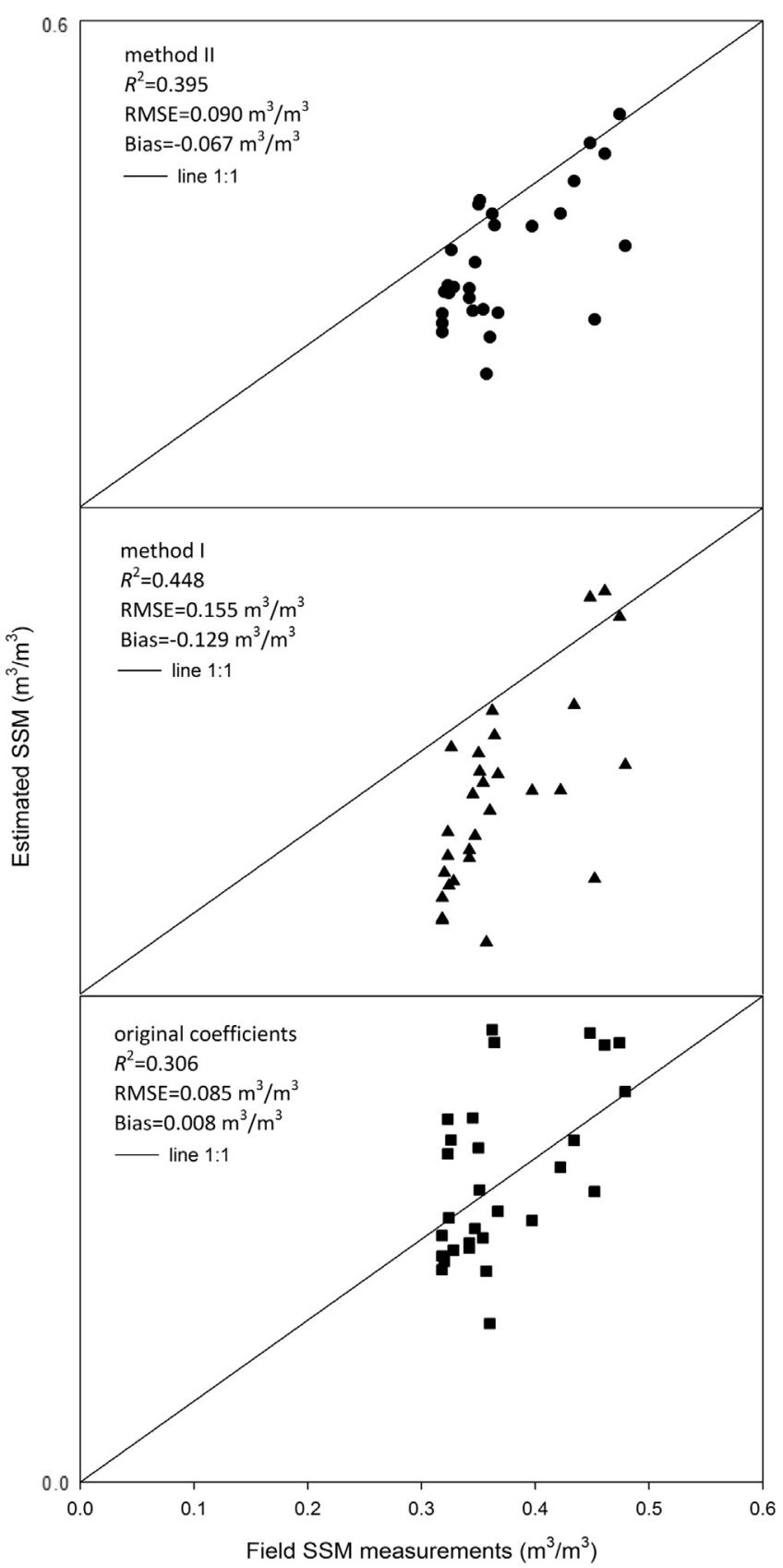

Fig. 7. Comparison between field SSM measurements and estimated SSM values based on model coefficients obtained via three approaches.

the original method. In particular, method II displays an RMSE that is similar to that of the original method, indicating that the proposed methods are generally feasible. The large Biases exhibited by method I and method II can be attributed to several factors, including the limited calibration period, field measurement errors and uncertainties in the SSM retrieval model. In addition, SSM measurements were measured at a depth of $10 \mathrm{~cm}$ in the top soil layer at YCES, whereas the estimated SSM is based on a layer depth of $5 \mathrm{~cm}$. This discrepancy may slightly influence the accuracy of this preliminary investigation. Nevertheless, because method I and method II only require daily maximum solar radiation to obtain the constant term $n_{0, \text { new }}$, they provide approaches for using the SSM retrieval model when meteorological measurements are not available to determine the model coefficients via the original method.

Fig. 8 compares field SSM measurements and estimated SSM values after a Bias correction based on the model coefficients

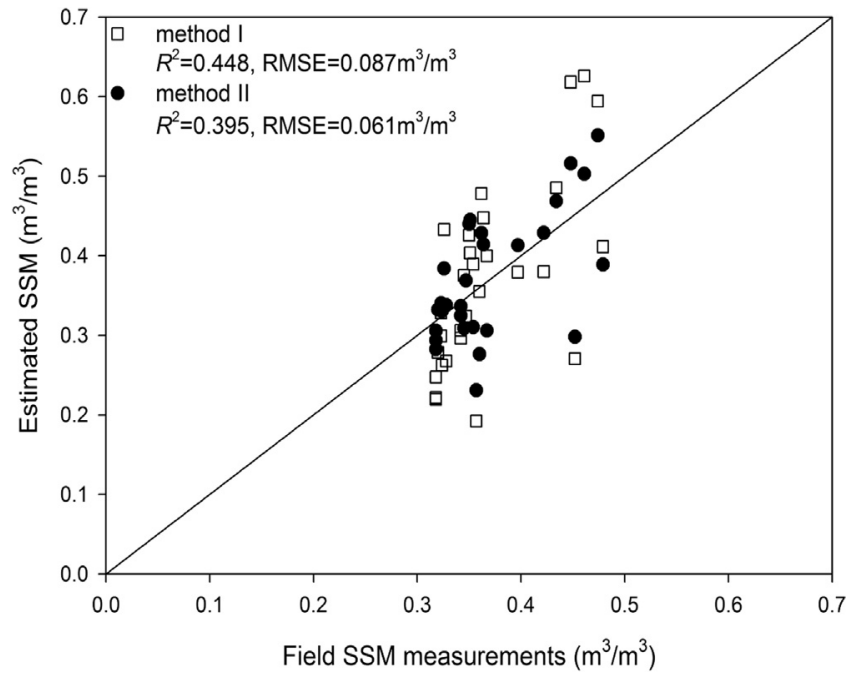

Fig. 8. Comparison between field SSM measurements and estimated SSM values with model coefficients obtained via method I and method II. A simple calibration was conducted to adjust the Biases.

obtained using method I and method II. Both method I and method II exhibit significant RMSE decreases. The method I RMSE decreased from $0.155 \mathrm{~m}^{3} / \mathrm{m}^{3}$ to $0.087 \mathrm{~m}^{3} / \mathrm{m}^{3}$, and the method II value decreased from $0.090 \mathrm{~m}^{3} / \mathrm{m}^{3}$ to $0.061 \mathrm{~m}^{3} / \mathrm{m}^{3}$. In general, both methods exhibited the potential for estimating model coefficients for SSM retrieval. However, method II is considered the preferred approach for obtaining the model coefficients at YCES.

\section{Discussion}

The present study primarily developed a new algorithm for estimating SSM from combined optical and thermal infrared measurements. The main achievement is that the time-invariable coefficients in the new algorithm can be obtained by historical meteorological records, allowing a more practical way to implement the SSM retrieval model, in comparison to the original manner that the model coefficients must be determined with numerous simulated datasets generated from complicated land surface model simulation process day by day.

Although a number of studies have explored the methods for estimating SSM from remotely sensed data, most of the currently available optical and thermal infrared-based algorithms can only obtain a SSM-related index or proxy of SSM (e.g. the Temperature Vegetation Dryness Index (TVDI) and the apparent thermal inertia). Moreover, various empirical or statistical relationships between remotely sensed parameters (index or proxy) and ground SSM are usually required to retrieve SSM in regional scale. In general, these empirical or statistical relationships have several disadvantages. For example, because the empirical coefficients in the relationships between SSM and apparent thermal inertia are identified to vary with soil textures, a default value is usually used to represent underlying soil texture in regional scale, which is most likely to lead to uncertainties in SSM estimation. Furthermore, the timevariable coefficients in these algorithms must be calibrated for each scene of remotely sensed image in theory to obtain accurate SSM, making it not that easy to apply with actual satellite images, especially for estimating SSM time series. Specifically, a large amount of ground SSM measurements are usually required to calculate the time-variable coefficients in the calibration process. In comparison to the previous optical and thermal infrared-based algorithms, the proposed method has overcome most of these drawbacks for SSM estimating. In summary, the practical SSM retrieval algorithm presented in this study features at least three advantages: (1) the 
algorithm is independent of soil texture that enables to obtain the more needed quantitative soil volumetric water content directly; (2) SSM measurements (either from in situ observations or satellites) are theoretically not necessary when using the historical meteorological records to determine the time-invariable coefficients; (3) fully using the historical meteorological records can effectively decrease the dependence of coefficients on the meteorological measurements, allowing an practical and easy to apply manner of the SSM retrieval algorithm with geostationary satellite images in future developments.

In the traditional optical and thermal infrared-based SSM retrieval algorithms, remotely sensed instantaneous surface variables are usually recognized as the direct inputs to estimate SSM, whereas in the proposed algorithm, parameters describing the temporal evolution of remotely sensed surface variables, rather than the direct surface variables, are implemented to estimate SSM. It is evident that errors of the direct inputs of the remotely sensed surface variables can transfer to the estimated result directly, which is most likely to lead to the uncertainty in SSM retrieval. On the contrary, using the temporal information can effectively decrease the sensitivity of errors of the remotely sensed surface variables to the SSM estimation. Several studies have also highlighted the advantages of using temporal information to estimate surface parameters from remotely sensed observations (Duan et al., 2014b; Lu et al., 2014).

In addition to the advantages, the proposed algorithm for estimating SSM can obtain an acceptable accuracy with RMSE around $0.60 \mathrm{~m}^{3} / \mathrm{m}^{3}$. In general, this accuracy of combining optical and thermal infrared data is comparable with others typical methods, e.g. the combining optical and microwave algorithm (Mattar et al., 2012), the combining optical and thermal infrared method (Sobrino et al., 2012), and the approach by synergistic using of optical/thermal infrared and microwave data (Chauhan et al., 2003). Furthermore, the proposed algorithm is expected to be a more easy to apply method for SSM retrieval, especially for obtaining SSM time series. This is because the algorithm presented in this study only requires the daily maximum solar radiation as an input to calculate the constant term day by day, and the other time-invariable coefficients can be determined by historical meteorological measurements. Specifically, no ground SSM measurements are required for the calibration of the time-invariable coefficients, which make it principally easier to apply in practical applications.

Nevertheless, at least two major issues remain to be further investigated in the ongoing work. It notes that although the constant term $n_{0}$ exhibits quite significant linear relationship with daily maximum solar radiation, the slope and intercept vary by regions, which is most likely to make it difficult to obtain the constant term $n_{0}$ over a large scale accurately, e.g. in the continent scale. How to feature these differences as an exact algorithm describing the variation of the constant term and daily maximum solar radiation, is surely to be a great challenge for the further developments of SSM retrieval algorithm. Specifically, several factors, including the latitude, climate pattern, elevation and even terrain, should be seriously considered in the further investigation to characterize the effects on the obtaining of the constant term $n_{0}$ over large spatial scale. In addition to the model coefficients, obtaining of the accurate ellipse parameters from the geostationary satellite images is also quite significant for SSM retrieval. Although the present study primary uses the simulated data and in situ measurements, and the actual satellite images are not implemented, accuracy of the remotely sensed inputs (LST and NSSR) is sure to affect the results of SSM retrieval in future developments. For example, the LST products of the widely used Moderate-resolution Imaging Spectroradiometer (MODIS) is reported to be with a RMSE within $1 \mathrm{~K}$ ( Li et al., 2013a), whereas the accuracy of the LST products derived from the Meteosat Second Generation (MSG) is generally sug- gested to be within 1-2 K according to the official validation reports (http://landsaf.meteo.pt/), and this value is indicated to be about 1-3 K for the Chinese FengYun-2 (FY-2) according to several recent literatures (Qian et al., 2013; Jiang and Liu, 2014). Overall, it is essential to develop more reliable algorithms to obtain accurate LST and NSSR values from geostationary satellite data. Moreover, because satellites always observe the Earth with a different time and angle for pixels even in a same scene of image, it is quite necessary to improve the accuracy of SSM retrieval through a time and angular normalization process to obtain LST and NSSR in a unified observation time and angle. All these efforts are expected to provide more accurate inputs for the SSM retrieval algorithm, which will decrease the uncertainties for SSM estimation.

\section{Conclusions}

This study assessed the determination of model coefficients using historical meteorological records to develop a practical algorithm for estimating SSM from combined optical and thermal infrared data. Based on a previously developed SSM retrieval model and the assumption that the four model coefficients associated with the ellipse variables are constant, the newly calculated constant term was significantly correlated with the daily maximum solar radiation. Based on the CoLM-simulated data, two methods (method I and method II) were then used to determine the model coefficients based on historical meteorological records. In this approach, the constant term must be calculated via a simple linear prediction model based on daily maximum solar radiation. These findings considerably decrease the dependence of the model coefficients on meteorological measurements. Based on the simulated data, the results indicated an average RMSE of $0.042 \mathrm{~m}^{3} / \mathrm{m}^{3}$ associated with estimating SSM at the three FLUXNET sites on over 30 cloud-free days using model coefficients obtained via a synchronous approach (method II). In addition to the simulated data, a preliminary validation using ground SSM measurements was also conducted to verify the estimated SSM values at the YCES site. After a Bias correction, the preferred method for obtaining the model coefficients using historical meteorological records exhibited moderate accuracy, with $R^{2}=0.395$ and RMSE $=0.061 \mathrm{~m}^{3} / \mathrm{m}^{3}$ between the estimated SSM values and measured values.

In summary, this study successfully decreased the dependence of model coefficients on meteorological measurements. In particular, only daily maximum solar radiation is required to obtain the constant term used in the SSM retrieval model based on the use of historical meteorological records. This approach greatly simplified model coefficient acquisition compared to the original approach that involved a complicated land surface model simulation process with numerous meteorological measurements required for atmospheric forcing. This analysis significantly improves upon the previously developed SSM retrieval model with respect to the actual application using geostationary satellite observations.

\section{Acknowledgements}

The authors thank the FLUXNET and YCES for providing the meteorological measurements and soil moisture data. The work described in this publication has been supported by the National Nature Science Foundation of China (grant No. 41571367) and by the Project Funded by China Postdoctoral Science Foundation (grant No. 2015M581210).

\section{References}

AI-Yaari, A., Wigneron, J., Ducharne, A., Kerr, Y., de Rosnay, P., de Jeu, R., Govind, A., A.I-Bitar, A., Albergel, C., Muñoz-Sabater, J., Richaume, P., Mialon, A., 2014. Global-scale evaluation of two satellite-based passive microwave soil moisture 
datasets (SMOS and AMSR-E) with respect to land data assimilation system estimates. Remote Sens. Environ. 149, 181-195.

Adegoke, J., Carleton, A., 2002. Relations between soil moisture and satellite vegetation indices in the U.S. Corn Belt. J. Hydrometeorol. 3, 395-405.

Anderson, S., Udawatta, R., Seobi, T., Garrett, H., 2009. Soil water content and infiltration in agroforestry buffer strips. Agrofor. Syst. 75, 5-16.

Carrão, H., Russo, S., Sepulcre-Canto, G., Barbosa, P., 2016. An empirical standardized soil moisture index for agricultural drought assessment from remotely sensed data. Int. J. Appl. Earth Obs. 48, 74-84.

Ceballos, A., Scipal, K., Wagner, W., Martínez-Fernández, J., 2005. Validation of ERS scatterometer-derived soil moisture data in the central part of the Duero Basin, Spain. Hydrolo. Processes 19, 1549-1566.

Chauhan, N.S., Miller, S., Ardanuy, P., 2003. Spaceborne soil moisture estimation at high resolution: a microwave optical/IR synergistic approach. Int. J. Remote Sens. 24, 4599-4622.

Coopersmith, E., Cosh, M., Bindlish, R., Bell, J., 2015. Comparing AMSR-E soil moisture estimates to the extended record of the U.S. Climate Reference Network (USCRN). Adv. Water Resour. 85, 79-85.

Dorigo, W., de Jeu, R., 2016. Satellite soil moisture for advancing our understanding of earth system processes and climate change. Int. J. Appl. Earth Obs. 48, 1-4.

Draper, C., Mahfouf, J., Calvet, J., Martin, E., Wagner, W., 2011. Assimilation of ASCAT near-surface soil moisture into the SIM hydrological model over France. Hydrol. Earth Syst. Sci. 15, 3829-3841.

Duan, S., Li, Z.-L., Tang, B., Wu, H., Tang, R., 2014a. Generation of a time-consistent land surface temperature product from MODIS data. Remote Sens. Environ. 140, 339-349.

Duan, S., Li, Z.-L., Tang, B., Wu, H., Tang, R., 2014b. Direct estimation of land-surface diurnal temperature cycle model parameters from MSG-SEVIRI brightness temperatures under clear sky conditions. Remote Sens. Environ. 150, 34-43.

Eltahir, E., 1998. A soil moisture-rainfall feedback mechanism, 1. Theory and observations. Water Resour. Res. 34, 765-776.

Entekhabi, D., Rodriquez-Iturbe, I., 1994. Analytical framework for the characterization of the spacetime variability of soil moisture. Adv. Water Resour. 17, 35-45.

Falloon, P., Jones, C., Ades, M., Paul, K., 2011. Direct soil moisture controls of future global soil carbon changes: an important source of uncertainty. Global Biogeochem. Cycles 25, GB3010.

Ferguson, I., Jefferson, J., Maxwell, R., Kollet, S., 2016. Effects of root water uptake formulation on simulated water and energy budgets at local and basin scales. Environ. Earth Sci. 75, 316.

Henderson-Sellers, A., 1996. Soil moisture: a critical focus for global change studies. Global Planet. Change 13, 3-9.

Holzman, M., Rivas, R., Piccolo, M., 2014. Estimating soil moisture and the relationship with crop yield using surface temperature and vegetation index. Int. J. Appl. Earth Obs. 28, 181-192.

Jiang, G., Liu, R., 2014. Retrieval of sea and land surface temperature from SEVISSR/FY-2C/D/E measurements. IEEE Trans. Geosc. Remote. Sens. 52 , 6132-6140

Johnsson, H., Jansson, P., 1991. Water balance and soil moisture dynamics of field plots with barley and grass ley. J. Hydrol. 129, 149-173.

Laiolo, P., Gabellani, S., Campo, L., Silvestro, F., Delogu, F., Rudari, R., Pulvirenti, L., Boni, G., Fascetti, F., Pierdicca, N., Crapolicchio, R., Hasenauer, S., Puca, S., 2016. Impact of different satellite soil moisture products on the predictions of a continuous distributed hydrological model. Int. J. Appl. Earth Obs. 48, 131-145.

Leng, P., Song, X., Li, Z.-L., Wang, Y., 2013. Evaluation of the effects of soil layer classification in the Common Land Model on modeled surface variables and the associated land surface soil moisture retrieval model. Remote Sens. 5 , 5514-5529.

Leng, P., Song, X., Li, Z.-L., Ma, J., Zhou, F., Li, S., 2014. Bare surface soil moisture retrieval from the synergistic use of optical and thermal infrared data. Int. J. Remote Sens. 35, 988-1003.

Leng, P., Song, X., Li, Z.-L., Wang, Y., Wang, R., 2015. Toward the estimation of surface soil moisture content using geostationary satellite data over sparsely vegetated area. Remote Sens. 7, 4112-4138.

Lesaignoux, A., Fabre, S., Briottet, X., 2013. Influence of soil moisture content on spectral reflectance of bare soils in the $0.4-14 \mu \mathrm{m}$ domain. Int. J. Remote Sens. 34, 2268-2285.
Li, Z.-L., Tang, R., Wan, Z., Bi, Y., Zhou, C., Tang, B., Yan, G., Zhang, X., 2009. A review of current methodologies for regional evapotranspiration estimation from remotely sensed data. Sensors 9, 3801-3853.

Li, Z.-L., Tang, B., Wu, H., Ren, H., Yan, G., Wan, Z., 2013a. Satellite-derived land surface temperature: current status and perspectives. Remote Sens. Environ. $131,14-37$.

Li, Z.-L., Wu, H., Wang, N., Qiu, S., Sobrino, J., Wan, Z., Tang, B., Yan, G., 2013b. Land surface emissivity retrieval from satellite data. Int. J. Remote Sens. 34, 3084-3127.

Lu, J., Tang, R., Tang, H., Li, Z.-L., 2014. A new parameterization scheme for estimating surface heat fluxes with continuous surface temperature, air temperature, and surface net radiation measurements. Water Resour. Res. 50, 1245-1259.

Mattar, C., Wigneron, J.-P., Sobrino, J., Novello, N., Calvet, J., Albergel, C., Richaume, P., Mialon, A., Guyon, D., Jiménez-Muñoz, J., Kerr, Y, 2012. A combined optical-microwave method to retrieve soil moisture over vegetated areas. EEE Trans. Geosc. Remote. Sens. 50, 1404-1413.

Merlin, O., Bitar, A.I.J., Walker, J., Kerr, Y., 2010. An improved algorithm for disaggregating microwave-derived soil moisture based on red, near-infrared and thermal-infrared data. Remote Sens. Environ. 114, 2305-2316.

Mittelbach, H., Casini, F., Lehner, I., Teuling, A., Seneviratne, S., 2011. Soil moisture monitoring for climate research: evaluation of a low-cost sensor in the framework of the Swiss Soil Moisture Experiment (SwissSMEX) campaign. J. Geophys. Res. 116, D05111.

Notarnicola, C., Caporaso, L., Giuseppe, F., Temimi, M., Ventura, B., Zebisch, M., 2012. Inferring soil moisture variability in the Mediterrean Sea area using infrared and passive microwave observations. Can. J. Remote Sen. 38, 46-59.

Pan, M., Sahoo, A., Wood, E., 2014. Improving soil moisture retrievals from a physically-based radiative transfer model. Remote Sens. Environ. 140, $130-140$.

Pierdicca, N., Pulvirenti, L., Fascetti, F., Crapolicchio, R., Talone, M., 2013. Analysis of two years ASCAT- and SMOS-derived soil moisture over Europe and North Africa. Eur. J. Remote Sens. 46, 759-773.

Price, J., 1977. Thermal inertia mapping: a new view of the earth. J. Geophys. Res. 82, 2582-2590.

Qian, Y., Qiu, S., Wang, N., Kong, X., Wu, H., Ma, L., 2013. Land surface temperature and emissivity retrieval from time-series mid-infrared and thermal infrared data of SVISSR/FY-2C. IEEE J. Sel. Top. Appl. Earth Obs. 6, 1552-1563.

Sanchez-Mejia, Z., Papuga, S., 2014. Observations of a two-layer soil moisture influence on surface energy dynamic and planetary boundary layer characteristics in a semiarid shrubland. Water Resour. Res. 50, 306-317.

Sandholt, I., Rasmussen, K., Andersen, J., 2002. A simple interpretation of the surface temperature/vegetation index space for assessment of surface moisture status. Remote Sens. Environ. 79, 213-224.

Santamaría-Artigas, A., Mattar, C., Wigneron, J.-P., 2016. Application of a combined optical-passive microwave method to retrieve soil moisture at regional scale over Chile. IEEE J. Sel. Top. Appl. Earth Obs. 9, 1493-1504.

Seneviratne, S., Corti, T., Davin, L., Hirschi, M., Jaeger, E., Lehner, I., Orlowsky, B., Teuling, A., 2010. Investigating soil moisture-climate interactions in a changing climate: a review. Earth-Sci. Rev. 99, 125-161.

Sobrino, J., Franch, B., Mattar, C., Jiménez-Muñoz, J., Corbari, C., 2012. A method to estimate soil moisture from Airborne Hyperspectral Scanner (AHS) and ASTER data: application to SEN2FLEX and SEN3EXP campaigns. Remote Sens. Environ. $117,415-428$.

Tuttle, S., Salvucci, G., 2014. A new approach for validating satellite estimates of soil moisture using large-scale precipitation: comparing AMSR-E products. Remote Sens. Environ. 142, 207-222.

Wagner, W., Lemoine, G., Rott, H., 1999. A method for estimating soil moisture from ERS scatterometer and soil data. Remote Sens. Environ. 70, 191-207.

Wetzel, P., Atlas, D., Woodward, R., 1984. Determining soil moisture from geosynchronous satellite infrared data: a feasibility study. J. Clim. Appl. Meteor. 23, 375-391.

Zhao, W., Li, Z.-L., Wu, H., Tang, B., Zhang, X., Song, X., Zhou, G., 2013. Determination of bare surface soil moisture from combined temporal evolution of land surface temperature and net surface shortwave radiation. Hydrol. Processes 27, 2825-2833. 